\title{
pH-Responsive chromogenic-sensing molecule based on bis(indolyl)methene for the highly selective recognition of aspartate and glutamate
}

\author{
Litao Wang ${ }^{1,2}$, Xiaoming $\mathrm{He}^{1,2}$, Yong Guo ${ }^{1}$, Jian $\mathrm{Xu}^{1}$ and Shijun Shao*1
}

\section{Letter}

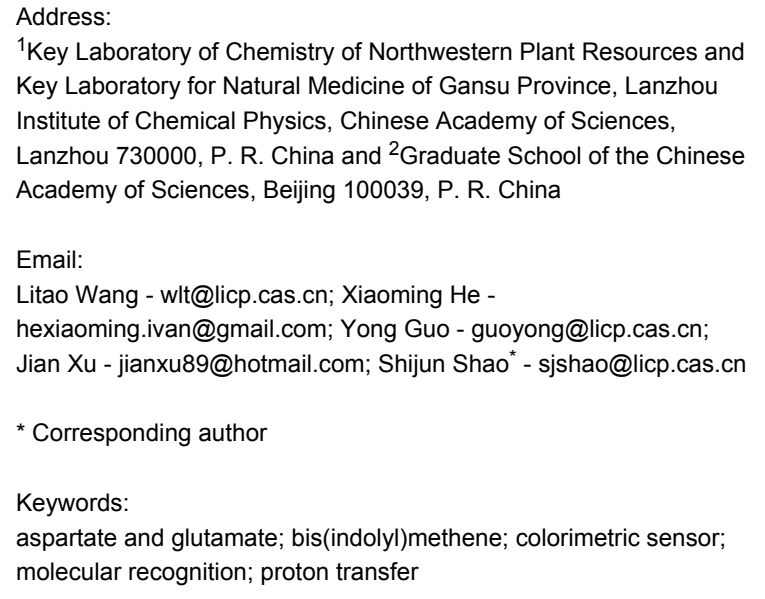

${ }^{1}$ Key Laboratory of Chemistry of Northwestern Plant Resources and Key Laboratory for Natural Medicine of Gansu Province, Lanzhou Institute of Chemical Physics, Chinese Academy of Sciences, Lanzhou 730000, P. R. China and ${ }^{2}$ Graduate School of the Chinese Academy of Sciences, Beijing 100039, P. R. China

Email:

Litao Wang - wlt@licp.cas.cn; Xiaoming He -

hexiaoming.ivan@gmail.com; Yong Guo - guoyong@licp.cas.cn;

Jian Xu - jianxu89@hotmail.com; Shijun Shao* - sjshao@licp.cas.cn

* Corresponding author

Keywords:

aspartate and glutamate; bis(indolyl)methene; colorimetric sensor; molecular recognition; proton transfer

Beilstein J. Org. Chem. 2011, 7, 218-221.

doi:10.3762/bjoc.7.29

Received: 31 October 2010

Accepted: 19 January 2011

Published: 16 February 2011

Associate Editor: S. C. Zimmerman

(C) 2011 Wang et al; licensee Beilstein-Institut.

License and terms: see end of document.

\begin{abstract}
Bis(indolyl)methene displays high selectivity and sensitivity for aspartate and glutamate in water-containing medium based on the proton transfer signaling mode. The presence of acid can easily induce proton transfer to the basic H-bond acceptor moiety, which modulates the internal charge transfer state of the bis(indolyl)methene skeleton and gives rise to dramatic change in color. The detection limits for aspartate and glutamate were $0.80 \mathrm{ppm}$ and $1.12 \mathrm{ppm}$, respectively.
\end{abstract}

\section{Introduction}

The development of artificial receptors for the selective recognition of biologically important species has attracted much attention [1,2]. However, compared to the large number of chromo/fluororeceptors for cations or anions [3-7], the development of artificial receptors for amino acids is quite limited. The effective and selective molecular recognition or sensing of unprotected amino acids in aqueous solution is still a challenging problem due to their highly hydrophilic character [8]. Several studies have shown that aspartate (Asp) and glutamate
(Glu) are important neurotransmitters [9-11], thus the recognition or sensing of these amino acids by synthetic receptor molecules is of great interest [12-14]. The bis(indolyl)methene molecule 1 (Figure 1), possessing an acidic H-bond donor moiety and a basic H-bond acceptor moiety, could act not only as a color-reporting group but also as a binding affinity control group. The anion sensing properties of $\mathbf{1}$ based on acidic $\mathrm{H}$-bond donor moiety have been studied previously in our laboratory [15]. The strong hydrogen bonding to, or proton- 
ation/deprotonation of, the indolyl moiety modulate the internal charge transfer (ICT) state of bis(indolyl)methene and give rise to large color changes. In aqueous solution, the effective recognition based on strong hydrogen bonding is hardly achieved because of the strong hydration to hydrogen bonding sites of both receptor and guest. However, the basic H-bond acceptor moiety of $\mathbf{1}$ is very sensitive to changes of $\mathrm{pH}$. Herein, we report a $\mathrm{pH}$-responsive chromogenic-sensing molecule $\mathbf{1}$ that shows high selectivity for Asp and Glu in a mixed acetonitrile/ water medium.

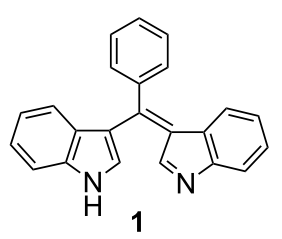

Figure 1: Structure of sensor 1.

\section{Results and Discussion}

The synthesis of $\mathbf{1}$ was according to previously described methods [15]. In acetonitrile receptor 1 produces a yellow solution and displays two strong absorption bands at 277 and 423 $\mathrm{nm}$ in acetonitrile (Figure 2a). The strong absorption band at $423 \mathrm{~nm}$ (hence the yellow color of the solution) can be assigned to $\pi-\pi^{*}$ transitions of the conjugated bisindole skeleton. A less strong shoulder peak at $500 \mathrm{~nm}$ is related to its intermolecular hydrogen bonding interaction and disappears on the addition of a small quantity of a polar protic solvent such as $\mathrm{CH}_{3} \mathrm{OH}$ or $\mathrm{H}_{2} \mathrm{O}$ to the solution. In the presence of $0-0.10 \mathrm{~mL} \mathrm{H}_{2} \mathrm{O}$, the intensity of the band at $423 \mathrm{~nm}$ increases slightly, while the shoulder at $500 \mathrm{~nm}$ disappears, which suggests that $\mathrm{H}_{2} \mathrm{O}$ disturbs the intermolecular hydrogen bond assembly of $\mathbf{1}$ itself. On further increasing the water content according to various ratios of the acetonitrile/water (total volume $=4 \mathrm{~mL}$ ), the band at $423 \mathrm{~nm}$ of receptor 1 shifts to $435 \mathrm{~nm}$ as a result of the solvent effect (Figure 2b). Moreover, the absorption band at 435 $\mathrm{nm}$ decreases when the ratio of the acetonitrile to water reaches 4:6 ( $/ \mathrm{v})$, which is probably related to the solubility of $\mathbf{1}$. As a result, the amino acid recognition and sensing properties of $\mathbf{1}$ were investigated in acetonitrile/water in a 1:1 (v/v) ratio.

Next, the pH-dependent spectral properties of 1 were studied in acetonitrile/water. As shown in Figure 3a, when $\mathrm{pH}<6(\mathrm{AcOH}$ and $\mathrm{NaOH}$ were used to adjust the $\mathrm{pH}$ values of the solutions), the notable spectral response of receptor 1 at $500 \mathrm{~nm}$ could be observed and almost reached a maximum at $\mathrm{pH}=3$. This is due to protonation of receptor $\mathbf{1}$ which is very sensitive to slight $\mathrm{pH}$ changes in aqueous acidic medium. However, in the $\mathrm{pH} 7-10$ range, no obvious spectral changes of 1 were observed. With increasing $\mathrm{pH}$ of the solution (Figure $3 \mathrm{~b}$ ), a new absorption band appeared at $517 \mathrm{~nm}$ due to the deprotonation of $\mathbf{1}$ [15]. The processes taking place can be summarized as follows:

$$
\mathrm{H}_{2} \mathrm{~L}^{+} \underset{+\mathrm{H}^{+}}{\stackrel{\mathrm{pH}<6}{\stackrel{\mathrm{m}}{ }}} \mathrm{- \textrm {H } ^ { + }} \underset{\mathrm{LH}}{\stackrel{\mathrm{L}}{-}}
$$

We then made use of the sensitivity of receptor 1 towards slight changes in $\mathrm{pH}$ to investigate the sensing properties for 20 natural amino acids using UV-vis spectroscopic techniques. As shown in Figure 4a, upon the addition of 25 equiv of amino acids in acetonitrile/water $(1: 1, \mathrm{v} / \mathrm{v})$, only Asp and Glu gave rise to perceptible spectral changes with the effect of changing the color of the solution instantly from yellow to red. This gives the
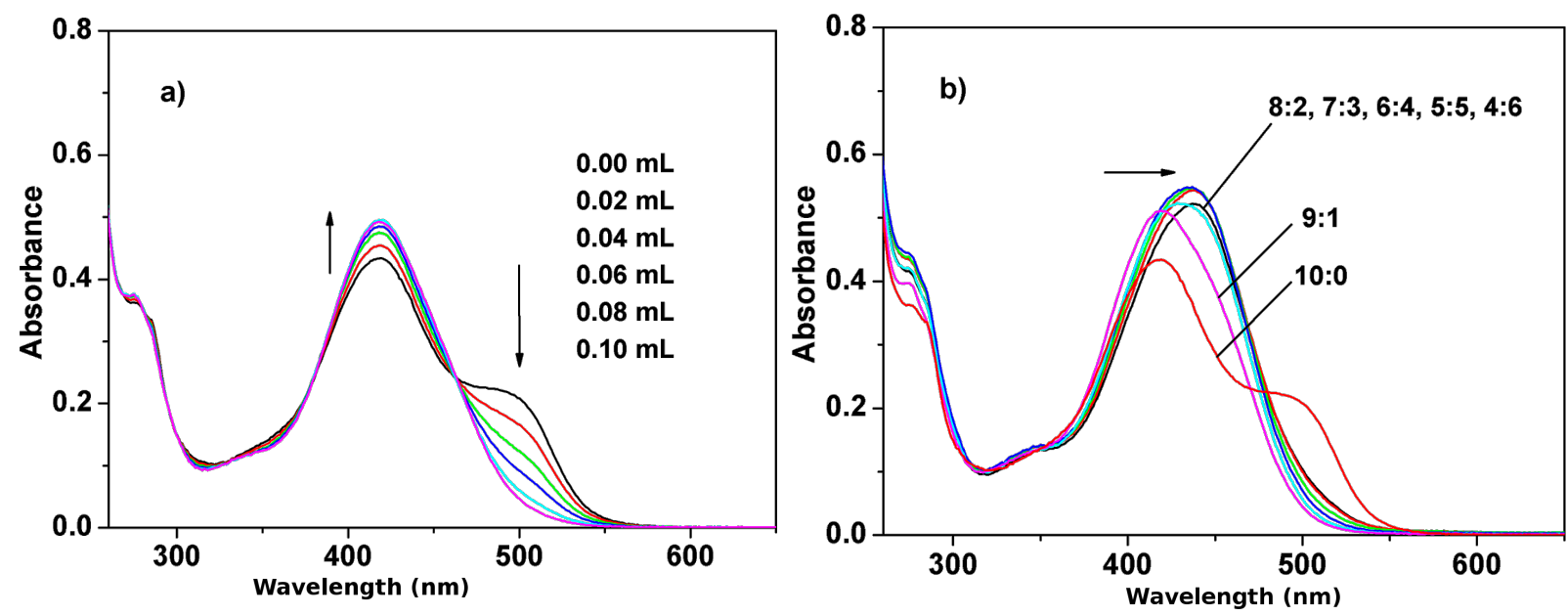

Figure 2: Changes in UV-vis spectra of $1\left(5.0 \times 10^{-5} \mathrm{M}\right)$ after addition of: (a) $0-0.10 \mathrm{~mL} \mathrm{H}_{2} \mathrm{O}$; (b) various ratios of the $\mathrm{CH}_{3} \mathrm{CN} / \mathrm{H}_{2} \mathrm{O}(\mathrm{fixed}$ volume is $4 \mathrm{~mL})$. 

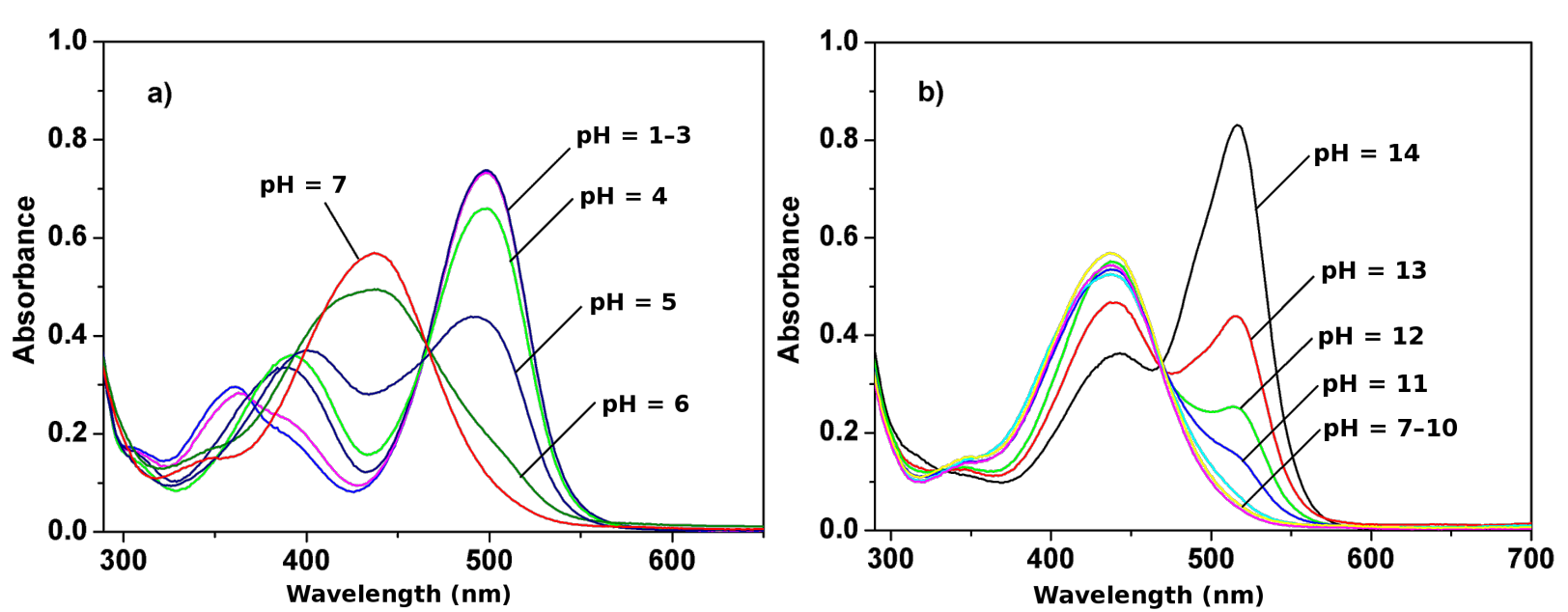

Figure 3: pH-dependent changes in UV-vis spectra of $1\left(5.0 \times 10^{-5} \mathrm{M}\right)$ in $\mathrm{CH}_{3} \mathrm{CN} / \mathrm{H}_{2} \mathrm{O}(1: 1, \mathrm{v} / \mathrm{v})$ at (a) $\mathrm{pH}=1-7$, and $(\mathrm{b}) \mathrm{pH}=7-14$.

potential for "naked eye" detection. With increasing concentration of Asp, the absorption band at $435 \mathrm{~nm}$ decreased accompanied with a blue-shift to $388 \mathrm{~nm}$ and at the same time a new strong absorption band at $500 \mathrm{~nm}$ continuously increased in intensity until it reached a maximum upon the addition of 5 equiv of Asp (Figure 4b),. This is responsible for the observed color change of the solution. A well-defined isobestic point at $466 \mathrm{~nm}$ suggests the formation of stable protonated complex and a simple one step equilibrium [16,17]. The titration spectra of the Glu almost resembled that of Asp. A similar, but less remarkable spectral change was observed upon addition of cysteine. On the other hand, no noticeable changes in color and absorption spectra were observed in the presence of various neutral amino acids and basic amino acids under the same conditions (even at much higher amino acids concentrations), which means that the receptor 1 exhibits negligible perturbation. The detection limits for Asp and Glu were determined to be $0.80 \mathrm{ppm}$ and $1.12 \mathrm{ppm}$, respectively $[18,19]$. These results indicate that the receptor $\mathbf{1}$ has displayed high selectivity and sensitivity for Asp and Glu in water-containing medium.

The changes in color and absorption spectra may be ascribed to proton transfer to 1 . Because of the acidic characteristic of Asp $(\mathrm{pI}=2.77)$ and Glu $(\mathrm{pI}=3.22)[20]$, they are quite capable of protonating 1 , which modulates the internal charge transfer (ICT) and results in a drastic spectral change from $435 \mathrm{~nm}$ to $500 \mathrm{~nm}$ arising from the protonated receptor $\left[\mathrm{H}_{2} \mathrm{~L}\right]^{+}$. For cysteine, due to its slight acidity compared to neutral and basic amino acids, it may also partly protonate $\mathbf{1}$, however, the spectral change observed does not achieve the same level as the
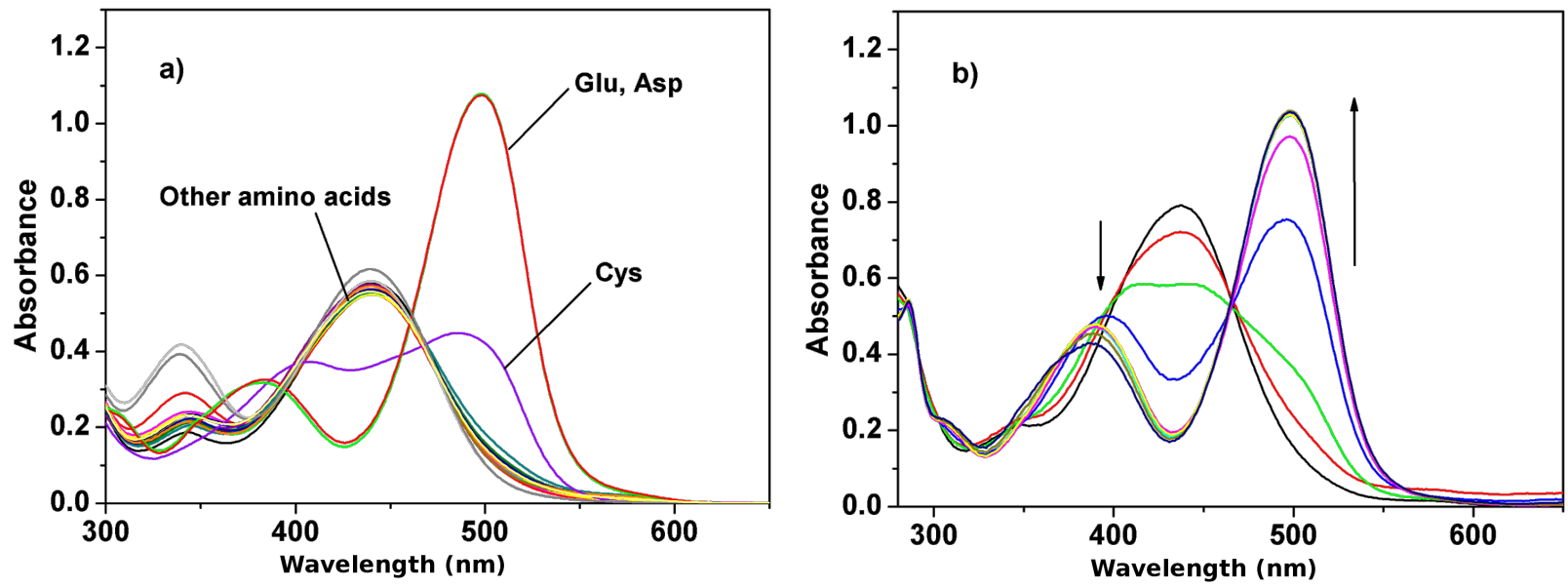

Figure 4: Changes in UV-vis spectra of $1\left(5.0 \times 10^{-5} \mathrm{M}\right)$ in $\mathrm{CH}_{3} \mathrm{CN} / \mathrm{H}_{2} \mathrm{O}(1: 1, \mathrm{v} / \mathrm{v})$ after addition of: (a) 25 equiv of Gly, Ala, Val, Leu, Iso, Phe, Thr, Glu, Asn, Met, Ser, Pro, Trp, Lys, Arg, His, Tyr, Glu, Asp and Cys; (b) 0, 1, 2, 3, 4, 5, 8, 10, 20, 50, 100 equiv of Asp. 
acidic amino acids even in the presence of 100 equiv of cysteine. On the other hand, compared with a strong base $\mathrm{NaOH}$, the basicity of the basic amino acids (such as Arg or Lys) is not strong enough to induce deprotonation of $\mathbf{1}$. These results show the high selectivity and sensitivity of $\mathbf{1}$ towards the acidic amino acids in aqueous medium.

The ratio of acetonitrile to water does not affect the sensing of amino acids. In a mixed solution $\left(\mathrm{CH}_{3} \mathrm{CN} / \mathrm{H}_{2} \mathrm{O}, 3: 1, \mathrm{v} / \mathrm{v}\right)$ of $\mathbf{1}$, the addition of amino acids produced the similar effects. When ether was added to the red mixed solution (in $\mathrm{CH}_{3} \mathrm{CN} / \mathrm{H}_{2} \mathrm{O}, 1: 1$ ) of 1 and Asp/Glu (containing $5.0 \times 10^{-5} \mathrm{M} 1$ and $1.5 \times 10^{-3} \mathrm{M}$ Asp/Glu) and the mixture shaken carefully, the upper organic phase turned yellow, while the aqueous phase became colorless. This suggests that protonation is reversible.

\section{Conclusion}

In conclusion, bis(indolyl)methene, containing a conjugated bisindole skeleton, provides an easy-to-make, simple and efficient chromogenic-sensing molecule model based on the proton transfer signaling mode. In water-containing medium, the presence of acid can easily induce the proton transfer to the basic $\mathrm{H}$-bond acceptor moiety, which modulates the internal charge transfer state of bis(indolyl)-methene and gives rise to dramatic color changes. As a $\mathrm{pH}$-responsive colorimetric sensor for amino acids, the receptor shows high selectivity and sensitivity for Asp and Glu.

\section{Acknowledgements}

Support of this work from the National Natural Science Foundation of China (Grant No. 20672121) is grateful acknowledged.

\section{References}

1. Sinkeldam, R. W.; Greco, N. J.; Tor, Y. Chem. Rev. 2010, 110, 2579-2619. doi:10.1021/cr900301e

2. Chen, X.; Zhou, Y.; Peng, X.; Yoon, J. Chem. Soc. Rev. 2010, 39, 2120-2135. doi:10.1039/b925092a

3. Gale, P. A. Acc. Chem. Res. 2006, 39, 465-475. doi:10.1021/ar040237q

4. Späth, A.; König, B. Beilstein J. Org. Chem. 2010, 6, No. 32. doi:10.3762/bjoc.6.32

5. Castilla, A. M.; Conn, M. M.; Ballester, P. Beilstein J. Org. Chem. 2010, 6, No. 5. doi:10.3762/bjoc.6.5

6. Xu, Z.; Yoon, J.; Spring, D. R. Chem. Soc. Rev. 2010, 39, 1996-2006. doi:10.1039/b916287a

7. Xu, Z.; Kim, S. K.; Yoon, J. Chem. Soc. Rev. 2010, 39, 1457-1466. doi:10.1039/b918937h

8. Galan, A.; Andreu, D.; Echavarren, A. M.; Prados, P.; De Mendoza, J. J. Am. Chem. Soc. 1992, 114, 1511-1512. doi:10.1021/ja00030a074

9. Baughman, R. W.; Gilbert, C. D. J. Neurosci. 1981, 1, 427-439.

10. Nedergaard, M.; Takano, T.; Hansen, A. J. Nat. Rev. Neurosci. 2002, 3, 748-755. doi:10.1038/nrn916
11. Tomlin, E.; McLean, H.; Caveney, S. Insect Biochem. Mol. Biol. 1993, 23, 561-569. doi:10.1016/0965-1748(93)90029-R

12. Braeken, D.; Rand, D. R.; Andrei, A.; Huys, R.; Spira, M. E.; Yitzchaik, S.; Shappir, J.; Borghs, G.; Callewaert, G.; Bartic, C. Biosens. Bioelectron. 2009, 24, 2384-2389. doi:10.1016/j.bios.2008.12.012

13. Aitt-Haddou, H.; Wiskur, S. L.; Lynch, V. M.; Anslyn, E. V. J. Am. Chem. Soc. 2001, 123, 11296-11297. doi:10.1021/ja011905v

14. Bonizzoni, M.; Fabbrizzi, L.; Piovani, G.; Taglietti, A. Tetrahedron 2004, 60, 11159-11162. doi:10.1016/j.tet.2004.08.102

15. He, X.; Hu, S.; Liu, K.; Guo, Y.; Xu, J.; Shao, S. Org. Lett. 2006, 8 , 333-336. doi:10.1021/ol052770r

16. Simplicio, F. I.; Maionchi, F.; Filho, O. S.; Hioka, N.

J. Phys. Org. Chem. 2004, 17, 325-331. doi:10.1002/poc.732

17. Hu, S.; Guo, Y.; Xu, J.; Shao, S. Spectrochim. Acta, Part A 2009, 72, 1043-1046. doi:10.1016/j.saa.2008.12.042

18. The limit of detection (LOD) calculated using the equation $L O D=3 \times$ $\delta_{\text {black }} / \mathrm{m}$ (where $\delta_{\text {black }}$ is the standard deviation of the black; $m$ is the slope of the calibration plot).

19. Niu, H.-T.; Su, D.; Jiang, X.; Yang, W.; Yin, Z.; He, J.; Cheng, J.-P. Org. Biomol. Chem. 2008, 6, 3038-3040. doi:10.1039/b808589g

20. Roberts, E.; Sherman, M. A. Neurochem. Res. 1993, 18, 365-376. doi:10.1007/BF00967239

\section{License and Terms}

This is an Open Access article under the terms of the Creative Commons Attribution License (http://creativecommons.org/licenses/by/2.0), which permits unrestricted use, distribution, and reproduction in any medium, provided the original work is properly cited.

The license is subject to the Beilstein Journal of Organic Chemistry terms and conditions:

(http://www.beilstein-journals.org/bjoc)

The definitive version of this article is the electronic one which can be found at: doi:10.3762/bjoc.7.29 